\title{
Mejoras en el proceso productivo y modernización mediante sustitución y tecnologías limpias en un molino de arroz
}

(1) Carlos Najar A.

(2) José Alvarez Merino \begin{abstract}
RESUMEN
La producción de arroz, que comprende la
agricultura, procesos productivos y distribución,
requiere de análisis integrales a fin de mejorar su
eficiencia y competitividad. En este contexto, en
el presente trabajo, se propone mejoras que
redunden en la producción y productividad en un
molino de arroz ubicado en la región Arequipa.
Para tal fin se realiza un diagnóstico del proceso
productivo, un benchmarking con las empresas
del sector, así como se introducen conceptos de
producción más limpia.
Palabras Clave: Molinos de arroz, tecnologías limpias, proceso productivo.

IMPROVEMENTS IN THE PRODUCTIVE PROCESS AND MODERNIZATION Through Substitution AND Clean TECHNOLOGIES IN A RICE MILLING ABSTRACT

The rice production includes the agriculture, productive, and distribution process. There are the need of the integral analysis, with the purpose of improve their efficient and competitively. In this context are presented improvements that impact in the production and productivity in milling rice sited in Arequipa region. For that is making a productive process diagnostic, a benchmarking with the sector enterprises, and the introduction of more clean production concepts.
\end{abstract}

Key Words: Rice milling, clean technologies, productive process.

\section{INTRODUCCIÓN}

El arroz no tiene ningún tipo de subsidio en su producción, ni tampoco ningún programa de apoyo al sector agrícola. El gobierno compra arroz a los productores nacionales para apoyar programas sociales de alimentación, pero las cantidades que compra son muy limitadas. En cuanto a las negociaciones del TLC con EEUU, el Perú habría otorgado plazos de desgravación de 17 años para el caso del arroz (www.tlcperueeuu.gob.pe, 2006). La desgravación de este producto partirá de un arancel base de $52 \%$ y con un plazo largo de desgravación que contempla 4 años de gracia. La cuota de importación otorgada representa el $5 \%$ del consumo nacional aparente, cuyo promedio entre los años 2002 y 2004 fue de 1,5 millones de ton.

En el presente estudio, se incide en la optimización del diseño del proceso productivo en un molino de pilado de arroz. El estudio se hará en las instalaciones de un molino de arroz ubicado en el valle de Tambo, provincia de Islay, departamento de Arequipa. Se abarcará todas sus instalaciones, con capacidad de pilado de 1,0 ton / h. Esto comprende el diseño de procesos desde el área de recepción del arroz en cáscara, hasta el almacenamiento en sacos del producto final.

Los objetivos del estudio son la mejora de la eficiencia y la flexibilidad del proceso productivo, enfocándose en el rediseño de procesos, así como cambios en la tecnología y energía utilizada.

Si bien es cierto el molino posee una capacidad por debajo del promedio del sector ( 1 ton/h. versus las 1,57 ton/h. promedio del sector), este estudio se podrá adaptar a molinos del mismo rubro debido a la cuasi estandarización del proceso.

Este trabajo se estructura de la siguiente manera. Inicialmente se presentan tanto los antecedentes como el marco legal actual así como el abordaje metodológico. A continuación se muestra el estado situacional de la industria molinera de arroz a nivel nacional, su importancia, la producción nacional y regional así como una reseña de la cadena productiva. Luego, se desarrolla el marco conceptual, se hace referencia a los conceptos claves que servirán para el desarrollo de la investigación tales como análisis de procesos, introducción de tecnologías limpias y modernización, así como los lineamientos para su implementación. Después se realiza el diagnóstico interno de la empresa así como un benchmarking con respecto al sector, en el cual se da a conocer la situación actual en la que se encuentra la empresa y

\footnotetext{
1) Ingeniero Industrial. Profesor del Departamento de Ingeniería Industrial, PUCP

E-mail: cnajar@pucp.edu.pe

(2) Doctor en Ingeniería de la Producción. Profesor del Departamento de Ingeniería Industrial, PUCP

E-mail: alvarezjcar@hotmail.com
} 
la forma en la que actualmente se realiza el proceso productivo. Seguidamente se presenta el diseño del proceso y las propuestas de mejora para dicha empresa, orientados a la mejora de la eficiencia y la calidad, tomando en cuenta el diagnóstico y la evaluación de su situación actual tanto en aspectos productivos, económicos y ambientales. Finalmente se muestra las conclusiones de este trabajo en base a la investigación y al trabajo desarrollado.

\section{REALIDAD NACIONAL DE LA INDUSTRIA MOLINERADE ARROZ}

La canasta familiar está fuertemente influenciada por seis productos que son arroz, pan, fideos, papas, leches y carne de pollo. La importancia relativa del arroz en la canasta, debido a los hábitos de consumo, es tal que provee $24 \%$ de calorías y un $15 \%$ de proteínas (MINAG, 2006).

La industria arrocera peruana, donde el pilado es una de sus mayores etapas productivas, en las últimas décadas ha sufrido los efectos de la falta de financiamiento para la renovación y/o adquisición de modernos equipos, entre estos de secado, procesamiento, selección y almacenamiento, así como los efectos de la falta de poder adquisitivo, situación que no ha permitido la modernización en este campo.

El Departamento de Arequipa, que representa el $8 \%$ de la producción nacional, cuenta con una infraestructura moderna de dicha industria (comparada con el promedio nacional). El molino ubicado en el valle de Tambo, cuenta con una capacidad de 1 ton / h (20 sacos por hora de arroz pilado, 320 sacos al día durante dos turnos de trabajo de 8 horas cada uno). Actualmente en la localidad del molino, distrito de Punta de Bombón, no existe un molino que satisfaga la demanda de pilado de los agricultores.

El reglamento de calidad e inocuidad alimentaria para los granos de arroz (MINAG, 2005) norma el ingreso de arroz cáscara a los molinos, descuentos por impurezas y humedad, características y rendimientos de arroz pilado, subproductos y comercialización. Este reglamento también establece los límites máximos permisibles de tolerancia en la producción de subproductos.

\section{MARCOTEÓRICO}

\section{Producto}

Según Hidalgo (1989), la calidad del grano depende en un $70 \%$ del acondicionamiento físico que ha tenido el arroz cáscara, y en un $30 \%$ al equipo utilizado para el pilado. Este último aspecto estará en función del tipo de maquinaria, condiciones, estado y regulación de cada una de ellas.

El tipo de arroz cáscara cultivado y pilado en la región del molino es la especie NIR-I, del cual se obtiene el arroz pilado, el cual es un producto de gran demanda en el mercado nacional, destinado en su totalidad al consumo humano.

El arroz pilado se clasifica por su calidad en arroz extra superior y corriente, teniendo en cuenta porcentajes de grano quebrado, materia extraña, grano dañado y olor.

\section{Subproductos}

Los subproductos obtenidos del arroz, tales como el arrocillo (granos quebrados), ñelen (menor a $1 / 4$ de tamaño del arroz normal), polvillo (arroz en polvo) y pajilla.

\section{Factores que determinan la calidad molinera en el arroz}

Los principales factores que determinan la calidad molinera en el arroz son la capacidad de un campo para producir los mayores porcentajes de grano entero y pulido y tener alto rendimiento total de pila cuando el arroz sea sometido al proceso de descascarado y blanqueado en los molinos. Por lo tanto, los factores que determinan la calidad molinera del grano de arroz son genéticos y ambientales.

\section{Proceso}

El pilado de arroz cáscara consiste en remover del grano cosechado y seco, las glumas (descascarado), los tegumentos y el embrión que corresponden a la estructura de la cariópside y constituye el salvado o polvillo; para producir arroz pulido o blanco con un mínimo de grano quebrado y de impureza final.

A continuación se describe el proceso productivo (figura 1):

a. Recepción: El arroz cáscara llega del campo en sacos de yute con $50 \mathrm{Kg}$

b. Inspección: Se realiza el control de humedad y de porcentaje de impurezas

c. Pesado: En balanza de 100kg.

d. Secado: Proceso muy importante que requiere de un tiempo prudencial. Si el secado es muy lento, se permite el desarrollo de microorganismo por el alto contenido de humedad, lo cual provocará un calentamiento de la masa y en consecuencia un deterioro del mismo. Por otro lado, si el secado es 
muy rápido se corre riesgo de que el grano sufra daños en su cariópside y la muerte del embrión a causa del excesivo calor.

Para realizar este proceso, existen dos métodos:

- convección natural: la energía solar es utilizada directamente sobre el grano.

- convección forzada: a través de un soplador, el aire que transportará el calor a la masa del grano.

e. Almacenaje: Se debe mantener las condiciones recomendadas de temperatura $\left(17^{\circ} \mathrm{C}\right.$ a $\left.18^{\circ} \mathrm{C}\right)$, humedad (humedad relativa del aire inferior al $65 \%$ o $70 \%$ ) y almacenamiento en medios pobres de oxígeno. Con ello se frenará el riesgo de degradación del grano y lograr un período de almacenamiento más grande.

f. Limpieza: Este proceso se realiza por la exposición de los granos a corrientes de aire y mallas cernidoras. Generalmente se realiza con un módulo compuesto de un ventilador-aspirador y zarandas o cribas.

g. Descascarado: Es la operación que consiste en separar la lenma, palea y gluma estériles, que constituyen la cáscara del arroz, dejando el endospermo y el embrión con su cubierta; mediante fricción por medio de piedras muelas o rodillos de hule.

h. Separación: Con el vaivén la máquina separa el grano en 3 grupos: paddy, paddy y grano moreno y grano descascarado moreno. El primero regresa a las descascaradora, el segundo grupo puede regresar a la mesa por el sinfín y el tercero pasa a la pulidora.

i. Blanqueado o Pulido: Proceso para remover del arroz moreno los tegumentos (capa fina grasos de color gris plata a veces rojo), el embrión y partículas de harina que quedan adheridas al grano, para darle un aspecto liso y brilloso (lustre).

j. Clasificación producto terminado: Proceso final que sirve para separar y seleccionar los granos quebrados, ñelen y partículas finas del grano entero, quedando listo para el pesado y ensacado.

k. Ensacado: El arroz pilado se comercializa a granel o en envases que permitan mantener sus características. Para ello se utilizan sacos nuevos con capacidad de $50 \mathrm{~kg}$. neto o, con menor capacidad según acuerdo con el productor o comerciante.
Figura 1. Obtención de arroz pilado en el molino.

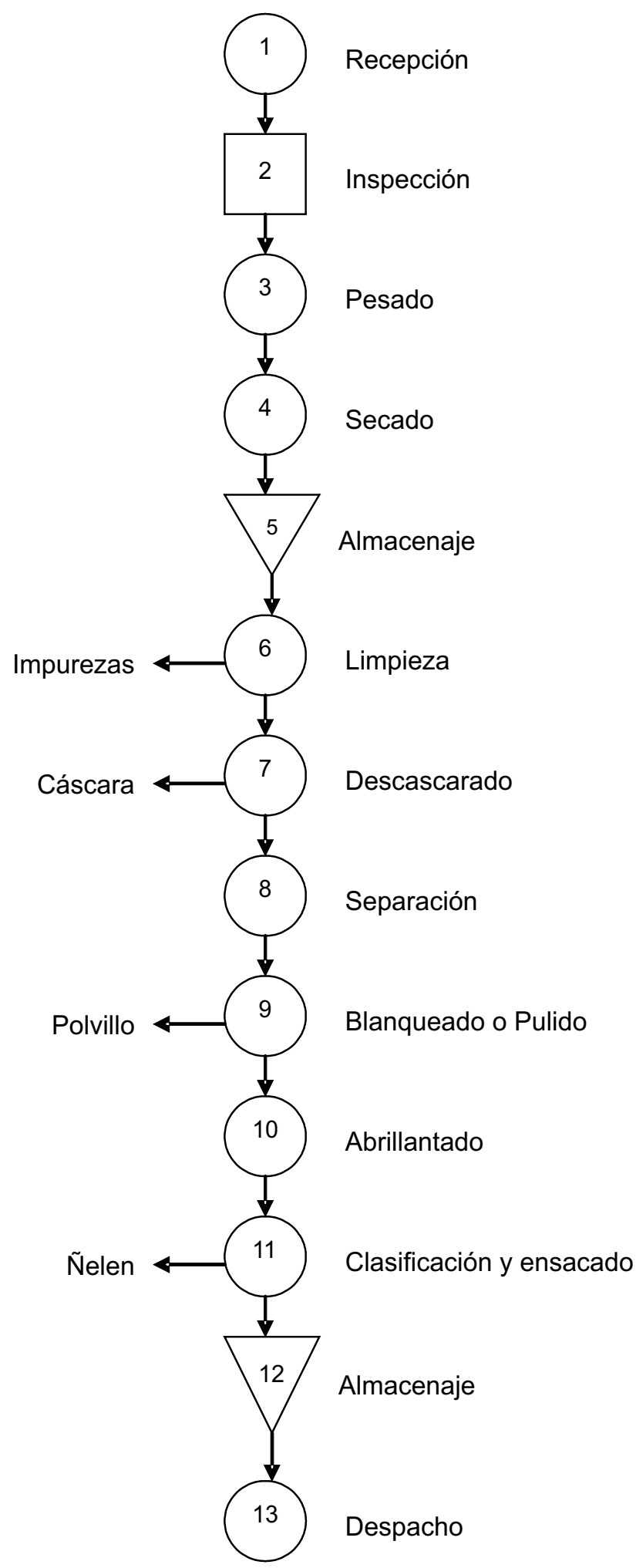


El Reglamento de Calidad e Inocuidad Alimentaria para los granos de Arroz, Decreto Supremo $N^{\circ}$ 023-2005-AG, indica que los molineros registrarán en los envases de arroz pilado el nombre del molino, ubicación, calidad comercial y peso. El medio de transporte usado no deberá transmitir al arroz pilado, características indeseables que impidan su consumo.

\section{Análisis del proceso}

Según Gonzáles (2002), la aplicación del análisis complejo de procesos se debe al desarrollo de las variedades de los productos así como a la elevación de la calidad de los mismos. Esto se observa en los últimos años, en donde la producción (en forma general) se enfocó en la elaboración de productos con menos gastos de energía, agua e inversiones, así como disminuyendo en gran medida la contaminación ambiental.

Esto en cierta medida puede contribuir a los siguientes logros:

- ahorro de energía

- garantizar el uso adecuado de los recursos naturales

- ampliar el aprovechamiento de las capacidades productivas

- mejorar progresivamente la capacidad de producción

- acelerar la introducción de los avances tecnológicos en la producción.

Así mismo, el análisis complejo de procesos consiste en un amplio análisis científico-técnico y técnicoeconómico de un proceso existente o concebido, en lo que corresponde a las posibilidades de optimizar los objetivos previstos. Es por ello que se considera un elemento importante para tomar decisiones científicas y responsables.

\section{Balance de masa y energía}

Se hará uso de balances cuantificados de los materiales que han entrado y los que han salido al proceso productivo, determinando los cambios en las existencias. Dichos balances se utilizarán para desarrollar un adecuado planeamiento y control de la producción, controles de rendimiento de materia prima y eficiencia de maquinaria, así como la demanda energética y de materiales necesarios (planeamiento logístico).

\section{Tecnologías limpias y modernización tecnológica}

Sustitución de la energía a base de combustibles por energía hidráulica y producción más limpia (PML), responden a una estrategia ambiental preventiva integrada a los procesos, a los productos y a los servicios para aumentar la eficiencia total y reducir los riesgos a los seres humanos y al ambiente.

Esta estrategia involucra típicamente la modificación de procesos de producción (utilizando energía hidráulica y cascarilla de arroz como combustible en el caso de la "empresa T"), usando un acercamiento de análisis de ciclo de vida, y resultando en resolver las necesidades del cliente con los productos y servicios ambientalmente compatibles. La PML también brinda ahorros económicos tangibles y beneficios financieros. Conceptos paralelos a la PML son: prevención de la contaminación, minimización de residuos, ecoeficiencia y productividad verde.

Así mismo se introducirán conceptos claves tales como la cogeneración como sistema de conversión energética. La tecnología de la cogeneración podría definirse como un sistema que partiendo de una energía de calidad media (la del combustible ó biomasa: cascarilla de arroz) la convierte en otras formas energéticas (de baja calidad, pero útil), como vapor en una caldera que podría ser usada en el secado de arroz por lecho fluidizado. Con la energía hidráulica también se podría generar electricidad muy útil para el proceso actual.

El secado por fluidización es una técnica para eliminar la humedad de un sólido mediante el paso de un gas, ó líquido, a través de un lecho donde se encuentra depositado el sólido. En lecho fluido, el producto a secar (en este caso el arroz cáscara) se vuelve fluido por la acción de un flujo ascendente de gas, reduciendo y ajustando la humedad del sólido a la deseada. En este caso, el gas es obtenido del vapor de una caldera que utiliza como combustible la cascarilla del arroz.

\section{DIAGNÓSTICO DEL PROCESOACTUAL}

Se realizará el diagnóstico productivo de la empresa así como un "benchmarking" (cuadro 1) con respecto al sector, en el cual se da a conocer la situación tecnológica y la forma en la que actualmente se realiza el proceso productivo.

\section{Diagnóstico del proceso productivo}

La "Empresa T" se encuentra ubicada en la zona de El Pino, distrito de Punta de Bombón, provincia de Islay del departamento de Arequipa. La edificación consta de dos pisos para el secado, un depósito o almacén y la sala de máquinas. Igualmente se tiene una pequeña planta hidroeléctrica inutilizada que servirá para suministrar energía al molino. Es uno de los molinos más antiguos de la zona (35 años), sin 
embargo debido a su buen mantenimiento viene funcionando, aunque no de manera eficiente.

En la región de Arequipa como en casi todo el Perú, la mayor parte de molinos arroceros operan como negocios individuales, existiendo unos pocos que lo hacen como sociedades anónimas o sociedades de responsabilidad limitada. En la actualidad, la dirección del negocio está a cargo del propietario, en la recepción de arroz cáscara, se ordena el pilado y se controla la entrega del arroz pilado.

La operatividad del molino se da a través de tres canales:

- El molino, pila el arroz cáscara a favor de los agricultores cobrándoles por tal servicio, en muchos casos se queda con el sub-producto.

- Comprando el arroz cáscara a todos aquellos agricultores que requieren obtener dinero para atender sus propias obligaciones y la siembra de la siguiente cosecha.

- Pilado de arroz propio proveniente de la cosecha de la campaña en curso.

Los propietarios del molino arrocero, muchas de las veces captan el arroz cáscara para pilado por relaciones de amistad con los agricultores de la zona. En otros casos, el aprovisionamiento se debe a la manera justa e idónea con que opera al momento de la recepción del arroz cáscara, como son servicio de pesado exacto, determinación de humedad de arroz cáscara de acuerdo al reglamento, determinación exacta de las impurezas del arroz cáscara.

\section{Diagnóstico de maquinaria y tecnología}

Para poder entender mejor la problemática actual del molino en estudio, es necesario realizar una comparación con ciertos parámetros representativos obtenidos de la industria molinera actual. Esto dará un buen índice para medir capacidades, limitaciones y eficiencia tanto de los procesos como de la maquinaria existente, para de esa manera poder determinar en forma efectiva los problemas, analizarlos e identificar las oportunidades de mejora de procesos y eficiencia.

Para realizar esta comparación, se utilizó "Los molinos de Arroz en el Perú" (MINAG, 2004). En esta, se identificaron un total de 695 molinos, los cuales se encuentran distribuidos en forma proporcional a la producción de arroz cáscara por departamento.

Para evaluar el molino, se tuvo en cuenta las siguientes características:

\section{a. Año de inicio de operaciones: antigüedad de maquinaria \\ Es el año en el cual el molino de pilado de arroz ha}

iniciado sus actividades productivas de transformación. Solo el $3 \%$ de los molinos presentan maquinaria con antigüedad anterior a los años ochenta. Dentro de este pequeño porcentaje se encuentra el molino estudiado.

\section{b. Área con maquinaria y equipo}

El $37 \%$ de los molinos poseen un área con maquinaria entre 37 y $144 \mathrm{~m}^{2}$. El Molino presenta un área total de maquinaria y equipo de $140 \mathrm{~m}^{2}$, encontrándose en el porcentaje mayor de molinos con dicha área.

\section{c. Capacidad de molienda}

La capacidad de molienda es uno de los principales indicadores para conocer si la empresa se encuentra en capacidad de satisfacer la demanda por pilado de arroz, siendo la capacidad promedio nacional alrededor de 1600 $\mathrm{Kg} / \mathrm{h}$.

El molino estudiado se encuentra con un capacidad de $1000 \mathrm{Kg} . / \mathrm{h}$, muy baja para satisfacer la demanda del distrito de la Punta de Bombón que es de alrededor de 7800 t de arroz cáscara (campaña 2005-2006).

d. Capacidad de almacenamiento de arroz cáscara para secado

Además de la capacidad en maquinaria y equipo, la capacidad de almacenamiento en arroz cáscara y arroz pilado son indicadores relevantes asociados al tamaño de los molinos y a su capacidad instalada. A nivel nacional permite determinar si ellos constituyen cuellos de botella para el desarrollo de la industria.

En total, la "empresa T" posee un área de 3300 $\mathrm{m}^{2}$, en los cuales se puede almacenar arroz en grano para su secado. Esto comparándolo con el promedio nacional resulta ser bastante ventajoso.

e. Maquinaria y equipo en limpieza

El molino estudiado cuenta con la suficiente capacidad para satisfacer los requerimientos de limpieza de grano para la línea de producción.

\section{f. Maquinaria y equipo en clasificación}

La clasificación es otra actividad relevante en el objetivo de obtener un grano de superior calidad al corriente. El molino estudiado se encuentra dentro de los 285 molinos que presentan este tipo de maquinaria.

g. Maquinaria y equipo en abrillantado

Es el punto más fuerte del molino, ya que sólo 36 molinos cuentan con este tipo de maquinaria. La 
Cuadro 1. Benchmarking aplicado al molino estudiado

\begin{tabular}{|l|l|l|l|}
\hline Medidas & "Empresa" & $\begin{array}{l}\text { Promedio } \\
\text { Nacional }\end{array}$ & Mayor \\
\hline Abrillantado $(\mathrm{kg} / \mathrm{h})$ & 1000 & 2000 & $3000^{* *}$ \\
\hline Clasificación $(\mathrm{kg} / \mathrm{h})$ & 1500 & 1000 & 6270 \\
\hline Limpieza $(\mathrm{kg} . / \mathrm{h})$ & 1500 & 1465 & 7333 \\
\hline Área secado $\left(\mathrm{m}^{2}\right)$ & 3300 & 4622 & 10000 \\
\hline Capacidad de molienda (Kg./h) & 1500 & 1636 & 12000 \\
\hline Antigüedad (Año) & 1975 & 1996 & 2003 \\
\hline Área con maquinaria $\left(\mathrm{m}^{2}\right)$ & 140 & 137 & 576 \\
\hline $\begin{array}{l}\text { Eficiencia de pilado (Kg.arroz pilado/Kg.arroz } \\
\text { cáscara) }\end{array}$ & 0.55 & 0.69 & $0.75^{\star *}$ \\
\hline Fuente: Elaboración Propia & \multicolumn{3}{|l}{ ** Se asume condiciones ideales }
\end{tabular}

capacidad de ambas abrillantadoras permite satisfacer los requerimientos de limpieza y abrillantado del producto.

\section{h. Eficiencia de pilado}

Actualmente la eficiencia en el proceso de pilado es quizás el punto más débil en cuanto al análisis comparativo. El promedio nacional de pilado de arroz se encuentra en 0,69 (es decir, por cada kg. de arroz en cáscara, sale $0,69 \mathrm{~kg}$. de arroz pilado). Para el caso del molino, este se encuentra en aproximadamente 0,55 , debido entre otros factores a deficiencias en el control de calidad de la materia prima, antigüedad de la maquinaria, entre otras. entero, quedando listo para el pesado y ensacado.

\section{PROPUESTA DE MEJORA PARA EL PROCESO PRODUCTIVO}

Las mejoras en el sistema productivo se pueden dar a través de dos medidas: utilización de una nueva línea de producción usando energía hidráulica, y utilización de secadora por lecho fluidizado empleando cáscara de arroz como combustible.

\section{Nueva línea de producción}

Se recurrirá a la instalación de una nueva línea de producción en reemplazo de la actual que requiere ser modernizada. Hay que tomar en cuenta que esta nueva línea utilizará energía hidráulica, renovable y limpia, proveniente de la minicentral hidroeléctrica existente pero inutilizada, la cual será repotenciada para dicho fin. La instalación de esta nueva línea permitirá satisfacer la demanda del servicio pilado para el $50 \%$ de agricultores del distrito de Valle de Tambo. Para poder identificar los nuevos parámetros de esta nueva línea de producción, primero se hará un estudio breve de la demanda en dicho distrito.

\section{Análisis de la demanda}

La producción de arroz cáscara durante las últimas 06 temporadas en el distrito de Punta de Bombón se detalla en el cuadro 2.

La producción de arroz cáscara en la provincia de Islay es de alrededor del $20 \%$ de la producción total

Cuadro 2. Producción de arroz cáscara en el distrito de Punta de Bombón, Valle de Tambo, Islay (2001 al 2006)

\begin{tabular}{|c|c|c|c|c|c|c|}
\hline Año/Temporada & $2000-01$ & $2001-02$ & $2002-03$ & $2003-04$ & $2004-05$ & $2005-06$ \\
\hline La Punta (ha) & 428.8 & 470 & 487 & 550 & 626.2 & 668.44 \\
\hline Islay (ha) & 2144 & 2350 & 2435 & 2750 & 3131 & 3342 \\
\hline Arequipa (ha) & 14724 & 15208 & 15211 & 15487 & 15707 & 16711 \\
\hline $\begin{array}{c}\text { Arroz cáscara La } \\
\text { Punta (TM.) }\end{array}$ & 4215.1 & 4309.9 & 5103.8 & 5863.0 & 7364.1 & 7887.6 \\
\hline $\begin{array}{c}\text { Rendimiento } \\
\text { Islay (T/Ha) }\end{array}$ & 9.83 & 9.17 & 10.48 & 10.66 & 11.76 & 11.8 \\
\hline
\end{tabular}

Fuente: DIA Arequipa 
Figura 2. Área destinada al cultivo de arroz en el distrito de Punta de Bombón (Arequipa) por campaña

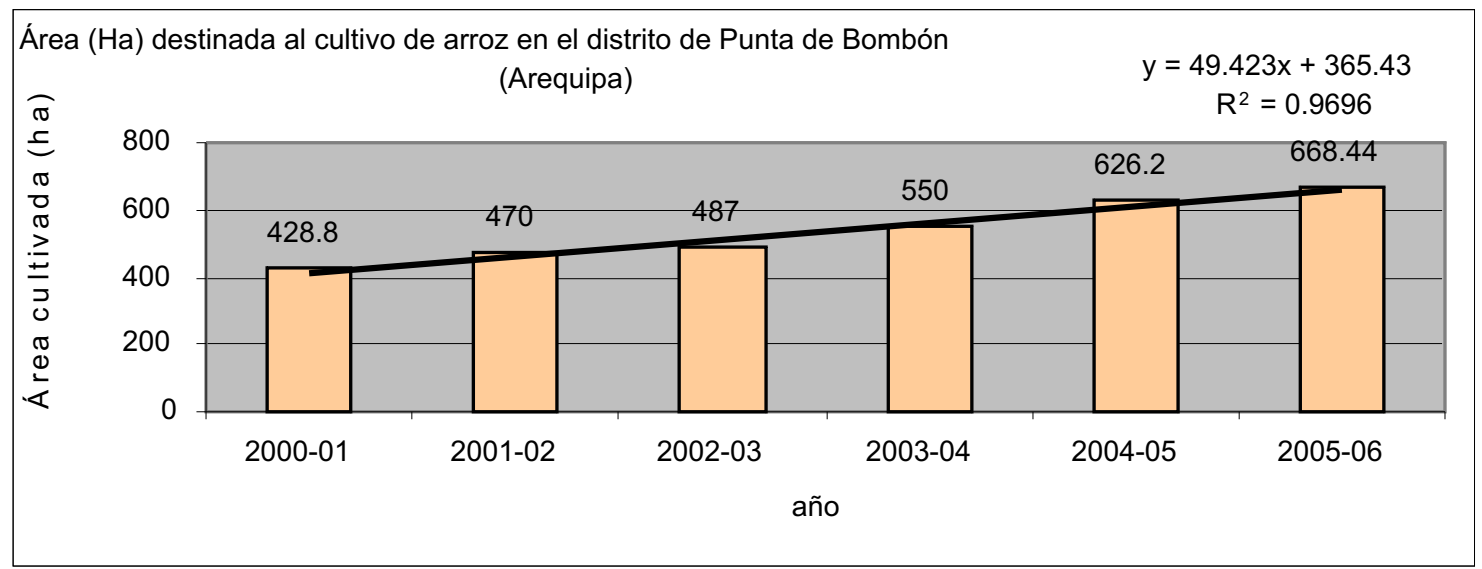

Fuente: DIA Islay - Arequipa

de la Región Arequipa, y el distrito de La Punta produce el $4 \%$ del total de la región. Actualmente la "empresa T", pila el $15 \%$ del total de arroz cáscara cosechado

\section{Servicio de Pilado}

Con estos datos se obtuvo la proyección del área a cultivar, así como la producción de arroz cáscara para los siguientes 5 años. Se tomó en cuenta para este último cálculo el rendimiento de arroz cáscara por hectárea del último año (11 ton / h) será constante para los próximo 5 años. El mercado objetivo para el servicio de pilado será del $50 \%$ del total de arroz cáscara producido en el distrito, es decir pilar alrededor de 3500 t en una temporada.

\section{Determinación de la capacidad de la nueva línea de producción}

Se tomarán como base los siguientes tiempos para la programación de la producción. Se parte de la suposición que la campaña fuerte de pilado se hace sobre los meses posteriores de cosecha. Se trabajará a 2 turnos, de lunes a sábado, asumiendo 4 meses de campaña de pilado.

Es decir, en total se disponen de 1536 horas por campaña. Para obtener la capacidad mínima requerida de pilado, se tendrá que dividir el arroz blanco pilado (asumiendo 68\% el rendimiento de pila) entre el total de horas disponibles en la campaña.

Cabe señalar que no se considera el arroz blanco propio de la "Empresa T". Por conveniencia y exigencia del mercado, se propone una estrategia a largo plazo, con una nueva línea con capacidad de $2000 \mathrm{~kg} / \mathrm{h}$ de arroz blanco pilado (datos de fábrica, capacidad nominal), ya que con ello se asegura el cumplimiento del servicio para un horizonte de 5 años como mínimo.

\section{Utilización de horno secador con cascarilla} de arroz

A la "empresa T", como a la gran mayoría de molineros, les representa un problema la eliminación de la cascarilla. Hasta ahora, su principal destino es el de alimento balanceado para animales y otros usos industriales. Pero hay muchas veces en las que no se le encuentra salida y hay que pagar para su eliminación bajo garantías medioambientales.

Para ello, se instalará un horno secador que emplee la cascarilla de arroz como combustible. Los principales objetivos que se pretende con este sistema son:

i.- Conversión de la cascarilla de arroz en un combustible de bajo costo a largo plazo y ecológico (reducción de las emisiones de $\mathrm{CO}_{2}$ )

ii.- Eliminar la cascarilla de arroz mediante su valorización energética.

iii.- Reducción del tiempo de secado, el cual representa aproximadamente el $50 \%$ del total del tiempo de producción.

Para la instalación de dicho horno, hay que tener en cuenta los siguientes requisitos específicos:

- Almacenamiento de la biomasa

- Preparación de la cascarilla y conducción al horno

- Sistemas de combustión especiales: Combustión en lecho fluidizado.

- Control de las emisiones a la atmósfera: partículas, NOx, CO

- Retirada de escorias y cenizas

Determinación de la capacidad de Secado

No puede pretenderse instalar una capacidad de 
secado igual o mayor que las máximas recepciones diarias de grano húmedo, pues significaría una inversión excesiva. Conviene calcular el promedio de las proyecciones de recepción diaria de grano húmedo en toda la temporada, y fijar una capacidad de secado mayor a ese dato. La capacidad mínima necesaria de la secadora es de 2,62 t/h. Por condiciones de disponibilidad (datos de fábrica) se utilizará una secadora de $5 \mathrm{t}$.

\section{Diseño por sustitución energética}

Se pretende la adaptación de un molino dedicado a la molienda de arroz para que sea utilizado mediante la generación de energía eléctrica utilizando una minicentral hidroeléctrica. Lo que se persigue es un cambio de uso de energía, para lo cual se debe llevar a cabo el mantenimiento de la turbina existente y la adaptación necesaria de los equipos electromecánicos en el interior de la misma.

Para el aprovechamiento de esta energía hidráulica únicamente se precisa el mantenimiento de la turbina existente, así como la instalación de los nuevos equipos de protección eléctrica. No es necesaria la realización ni adaptación de nuevos canales para la consecución de una mini generadora hidroeléctrica, ya que existe un canal con un desnivel, en la cual existe una turbina de generación. En este caso, se realizarán únicamente las obras necesarias en el interior del edificio del molino, donde se dará mantenimiento a la turbina para la producción de electricidad.

Además de ello, se instalará un horno secador que emplee la cascarilla de arroz como combustible. Para ello se empleará el método del secado en lecho fluidizado. Con este se pretende reducir el tiempo de secado del molino en más del $90 \%$ del tiempo actual (20 días aproximadamente). Actualmente dicho proceso se hace utilizando la energía solar. Además, se eliminaría la cascarilla de arroz mediante una valorización energética.

1. Hidroeléctrica: Generación y consumo de electricidad de una minicentral instalada.

El fundo "El Pino", donde se encuentra el molino estudiado, cuenta con todos los componentes de una central hidroeléctrica, cuya infraestructura se encuentra en estado de abandono y no utilizada: bocatoma (sobre el río tambo Puente Freyre), canal de acceso (Santa Ana de Quitiri), cámara de carga y/o desarenador, canal de demasías, tubería de presión y tuberías de PVC, casa de máquinas y canal de descargas.

La caída de agua es de 10 metros. Todo este complejo puede producir en estado normal una potencia de aproximadamente $50 \mathrm{KW}$ continuos. Toda esta energía no sólo se destinaría al funcionamiento del molino arrocero, sino también a potenciales actividades paralelas como el dotar de fluido eléctrico a viviendas rústicas aledañas, inclusión de riego por goteo que use una bomba eléctrica, etc.

Con una mediana inversión, dicha minicentral podría perfectamente volver a funcionar y generar la energía necesaria para poner en funcionamiento el molino.

\section{Utilización de cáscara como combustible} para secado en horno:

Descripción de la tecnología de dos etapas para secado

El sistema consta de los siguientes componentes:

- Sistema de alimentación

- Abastecedor de aire

- Chimenea

- Cámara de combustión

- Intercambiador de calor

La cascarilla de arroz entra en la cámara de combustión por encima y se mueve hacia abajo sobre una cama caliente fija por gravedad. La tecnología de dos etapas se refiere a dos puertos de tomas de aire; el aire primario llega de pequeños orificios que se ubican en el fondo de la cama. El aire secundario entra encima de la cama y asegura la combustión completa. Los gases de combustión calientes son conducidos por un intercambiador de calor y se calienta el aire del ambiente a $100-200^{\circ} \mathrm{C}$ dependiendo de la aplicación. El aire caliente resultante es conducido para el secado utilizando sopladores.

Los mejores resultados son obtenidos con flujos de aire secantes altos (aproximadamente 25000 $\mathrm{m}^{3} / \mathrm{h}$ ) en temperaturas bajas (llegando en el horno a aproximadamente $100^{\circ} \mathrm{C}$ que más adelante es rebajada al mezclarse con aire ambiente hasta $\left.60^{\circ} \mathrm{C}\right)$.

\section{ANÁLISIS DE LAS PROPUESTAS DE MEJORA}

\section{Análisis del sector productivo}

El cuadro 3 presenta un analisis comparativo entre los tiempos de producción de la situación actual y la situación propuesta.

Con las nuevas propuestas de mejora, se logrará reducir los siguientes tiempo de producción: 
Cuadro 3. Tiempos de producción (días). Situación actual y propuesta.

\begin{tabular}{|l|r|r|r|r|}
\hline & ACTUAL & PROPUESTA & REDUCCIÓN & $\begin{array}{r}\text { REDUCCIÓN } \\
(\%)\end{array}$ \\
\hline PILADO DE ARROZ & \multicolumn{3}{|l|}{} \\
\hline $\begin{array}{l}\text { Tiempo promedio de producción } \\
\text { en el molino (sin secado) }\end{array}$ & 21.21 & 2.45 & 18.75 & $88.4 \%$ \\
\hline $\begin{array}{l}\text { Tiempo promedio de espera en } \\
\text { fila }\end{array}$ & 19.08 & 1.62 & 17.45 & $91.5 \%$ \\
\hline $\begin{array}{l}\text { Fracción de clientes que tienen } \\
\text { que esperar }\end{array}$ & $91.30 \%$ & $78.26 \%$ & $13.04 \%$ & $13.0 \%$ \\
\hline $\begin{array}{l}\text { Tiempo promedio de espera por } \\
\text { cliente que espera }\end{array}$ & 20.90 & 2.08 & 18.82 & $90.1 \%$ \\
\hline INCLUYENDO SECADO & 21.76 & 0.27 & 21.49 & $98.7 \%$ \\
\hline Tiempo promedio de secado & 42.97 & 2.73 & 40.24 & $93.7 \%$ \\
\hline $\begin{array}{l}\text { Tiempo promedio total de } \\
\text { producción }\end{array}$ & & & & \\
\hline
\end{tabular}

Fuente: Elaboración Propia

- Reducción del tiempo de pilado (sin secado) en 18.75 días $(88.4 \%)$

- Reducción del tiempo promedio de espera en cola en 17.45 días $(91.5 \%)$

- Reducción del tiempo promedio de secado en 21.49 días $(98.7 \%)$

- Reducción del tiempo promedio total de producción en 40.24 días (93.7\%).

Análisis económico: Recuperación de la inversión

Para lograr la financiación de la nueva línea de producción, se contará con recursos propios de la empresa Ty de la ONG suiza CET PERÚ.

El presente estudio visto como proyecto, permite recuperar la inversión (cuadro 4) en 4,2 años, teniendo un VAN económico de \$/.107,499 con proyecciones crecientes y un TIR económico de 27.4\%. El ratio Beneficio/Costo es de 1,15.

Análisis ambiental: Análisis del ciclo de vida Se realiza un análisis desde el punto de vista energético y su influencia sobre el medio ambiente en la producción arrocera de la empresa T. Para evaluar lo antes mencionado fue necesario realizar un análisis de inventario en cada etapa del proceso productivo identificando las entradas energéticas y desechos de salidas.

Para evaluar el impacto ambiental se utilizó la herramienta de gestión ambiental "Análisis de Ciclo de Vida" identificando el estado actual de los problemas medioambientales de efecto invernadero, acidificación y formación de partículas en suspensión, arribando como resultado que el consumo de combustible Diesel utilizado es el energético de mayor influencia.

Para la evaluación de los impactos medioambientales asociados al consumo de energía se procedió al análisis de la metodología propuesta anteriormente (sobre Análisis de Ciclo de Vida), clasificando los impactos más representativos asociados al consumo de energía, los mismos son: calentamiento global (efecto invernadero), acidificación, y formación de partículas en suspensión.

Cuadro 4. Total inversión en activos fijos. Alternativa propuesta

\begin{tabular}{|l|lr|}
\hline RUBRO & MONTO \\
\hline Molino para elaborar arroz marca Zaccaría & $\$ 124,677.82$ \\
\hline Hidroeléctrica: Instalaciones, rueda, compuerta y obras & $\$ 28,820.59$ \\
\hline Balanza electrónica, capacidad 10 000 kg & $\$$ & $26,200.00$ \\
\hline Horno de secado combustible cascarilla de arroz & $\$$ & $20,000.00$ \\
\hline TOTAL & $\$ 1$ & $199,698.41$ \\
\hline
\end{tabular}

Fuente: Elaboración Propia 
Cuadro 5. Medición emisiones: Situación actual y propuesta (Kg.)

\begin{tabular}{|l|c|c|c|}
\hline $\begin{array}{l}\text { Impacto } \\
\text { Ambiental }\end{array}$ & $\begin{array}{c}\text { Situación } \\
\text { actual }\end{array}$ & $\begin{array}{c}\text { Situación } \\
\text { propuesta }\end{array}$ & $\begin{array}{c}\text { Reducción/ } \\
\text { Aumento (\%) }\end{array}$ \\
\hline $\begin{array}{l}\text { Efecto } \\
\text { Invernadero } \\
\left(\mathrm{kg} \text { eq } \mathrm{CO}_{2}\right)\end{array}$ & $43,968.63$ & 389.73 & $-99.11 \%$ \\
\hline $\begin{array}{l}\text { Lluvia ácida } \\
\left(\mathrm{kg} \text { eq } \mathrm{SO}_{2}\right)\end{array}$ & 588.85 & 616.45 & $+4.68 \%$ \\
\hline $\begin{array}{l}\text { Partículas en } \\
\text { suspensión (Kg.) }\end{array}$ & 52.98 & 53.61 & $+1.19 \%$ \\
\hline
\end{tabular}

Fuente: Elaboración Propia

Se determinó la contribución de cada parámetro inventariado (diesel, electricidad y cáscara de arroz combustible) al impacto medio ambiental, mediante el cálculo de los productos emitidos por su utilización como fuente de energía. En el caso de la cáscara de arroz se determinó según Carrasco (2002).

En el cuadro 5 se observa las emisiones (Kg.) de la situación actual y las emisiones calculadas con las variables de las propuestas de mejora.

\section{CONCLUSIONES Y RECOMENDACIONES}

El molino pretende satisfacer la demanda de los agricultores arroceros del distrito de Punta de Bombón, en donde el único molino que pila arroz es la empresa T. En la actualidad se producen alrededor de 7800 ton de arroz cáscara, de las cuales más del $80 \%$ tienen que ser trasladadas por lo menos $10 \mathrm{Km}$. para poder ser procesadas en molinos de distritos cercanos. Esto representa un costo excesivo en transportes, tiempo y dedicación del agricultor para lograr el beneficio del producto.

Con la repotenciación del molino existente, se logrará un beneficio económico para los agricultores de la zona debido a la disminución en sus costos, así como el beneficio social de tener arroz pilado de consumo para toda la población en forma directa y cercana. La realización del presente estudio representa a futuro un beneficio económico bastante atractivo para los propietarios. Esto se refleja en aspectos claves tales como el aumento de la eficiencia de producción, ahorro de costos por sustitución energética y ordenamiento en todos los procesos productivos y administrativo.

Al ser bajo el índice de pilado en la actualidad, aumenta el retorno de arroz cáscara al proceso de descascarado, ocasionando mayores costos. Al repetir el procesamiento hay exceso en el gasto por mano de obra directa y manipulación, el uso de rodillos, combustible, entre otros.
Como se podrá observar el secado del arroz en el molino estudiado, resulta ser el "cuello de botella" porque retrasa el lead time total del proceso de pilado, ocasionándose pérdidas de clientes (los agricultores).

Diagnosticado el secado como el punto más débil del proceso productivo, se deberá recurrir al acondicionamiento de un sistema de secado de flujo continuo que permite aumentar el flujo de materia prima antes del descascaramiento, teniendo en cuenta la minimización de recursos económicos y materiales.

El proyecto tendrá un efecto positivo ya que permite optimizar el uso de recursos renovables existentes en detrimento del consumo de otro tipo de recursos no renovables y más contaminantes, como el combustible diesel utilizado en la actualidad.

La energía hidroeléctrica es una alternativa para la generación de energía eléctrica a base de petróleo. Actualmente, el molino viene funcionando mediante un motor a diesel, el cual emana dióxido de carbono.

\section{REFERENCIAS BIBLIOGRÁFICAS}

1. BTG World. Utilización de cascarilla de arroz para secado de arroz en horno de combustión. En: http://www.btgworld.com.

(Visitado: 02-09-06).

2. Carrasco García, Juan. E. (2002). Aspectos medioambientales de la producción y uso de la biomasa como recurso energético. CIEMAT.

3. Centro de Eficiencia Tecnológica CET PERÚ. En: http://www.cet.org.pe

(Visitado: 02-06-06).

4. Díaz, Bertha (2001). Disposición de Planta. Fondo Editorial Universidad de Lima. Lima, Perú. 
〉 Mejoras en el proceso productivo y modernización mediante sustitución y tecnologías limpias en un molino de arroz

5. Domínguez Machuca, José (1995). Dirección de Operaciones: Aspectos tácticos y operativos en la producción y los servicios. Mc Graw-Hill. España.

6. Fernández Díez Pedro. Turbinas Hidraúlicas 2004. En: http://www.termica.webhop.info/ (Visitado: 03-04-06).

7. Flores, J. (2003). Procesamiento, comercialización y distribución del arroz en el Perú. Universidad Nacional Agraria La Molina, tesis para optar el título de Ingeniero Agrónomo. Lima, Perú.

8. Hidalgo, G. (1989). Manejo del Arroz en la Industria Molinera: Normas y Procedimientos Técnicos. Empresa Comercializadora de Arroz S.A. Lima, Perú

9. International Standard Organisation (1997). Norma ISO 14042. Gestión Medioambiental. Análisis de Ciclo de Vida. Evaluación de Impacto de Ciclo de Vida.
10. Konz, Stephan (1992). Manual de Distribución en plantas industriales. Editorial Limusa.

11. Leidinger, Otto (1997). Procesos Industriales. Fondo Editorial Universidad Católica del Perú. Lima, Perú.

12. Ministerio de Agricultura del Perú (2005). Informe: Los Molinos de arroz en el Perú. Oficina de Estadística de la Dirección General de Información Agraria. Lima, Perú.

13. Ministerio de Agricultura del Perú (2005). Reglamento de calidad e inocuidad alimentaria para los granos de arroz. Lima, Perú.

14. Miranda, J. Estudio de Factibilidad para la instalación de un molino de pilar arroz. Pontificia Universidad Católica del Perú, tesis para optar el título de Ingeniero Industrial. 1991, 179 p, LimaPerú.

15. Unidad de Comunicaciones para el Tratado de Libre Comercio Perú - Estados Unidos. Ministerio de Comercio Exterior y Turismo. En: http://www.tlcperu-eeuu.gob.pe 